\title{
Srinivasachary SAMPATH*: Notes on the Taxonomy of the Genus Oryza
}

\author{
S. Sampath：イネ属の分類学的知見
}

Received November 25, 1960

An enumeration of the species of Oryza as well as a key to the genus has been prepared by Chatterjee $\left.^{1}\right)$. He recognizes 23 valid species from amongst the $30-40$ specific names published previously. Since this publication, three new species have been described, bringing the total to 26 . Though the genus is small, it is economically important and its taxonomy is of interest to workers tracing the interrelationships, origin, and evolution of cultivated rice. Kihara ${ }^{2}$ ) has drawn attention to some probable errors in nomenclature. The present author has committed some errors in the past and the notes given below are intended to rectify them, and also to assist others in this field. This note is based on cytogenetical studies on Oryza collection at the Central Rice Research Institute, Cuttack, and observations on the Oryza species and hybrids being grown at the National Institute of Agricultural Sciences, Hiratsuka

1) Oryza perennis Moench. Chatterjee ${ }^{1}$ ) includes under this specific name Asian, American, as well as African perennial wild rices. A group of African wild rices can be conveniently separated from $O$. perennis and renamed $O$. barthii A. Cheval. This species is characterized by erect habit, and strongly spreading rhizomes, as contrasted to the residual $O$. perennis, having weak rhizome development, and spreading, prostrate or floating habit. Both the species are adapted for outcrossing, but seed setting under selfing bags is partial in O. perennis, and nil in O. barthii. The failure to set seed on selfing, in $O$. barthii suggests self incompatibility, but, the observation needs confirmation. If self incompatibility exists, it is a distinctive feature, and a new specific name is justifiable. As far as is known, $O$. barthii and $O$. perennis have allopatric distribution, and hybridization between the two is difficult, and artificial cross pollinations have been hitherto unsuccessful.

2) o. cubensis. The variety of wild rice occurring in Cuba must be included under $O$. perennis and Chatterjee ${ }^{1}$ ) does not record $O$. cubensis as a validly published name. The plants hitherto collected and grown have a semi-erect habit as contrasted to the floating or prostrate habit of Asian $O$. perennis, and since they are geographically isolated from the latter, can be given a varietal status, namely $O$. perennis var. cubensis.

3) 0. paraguaensis. There is no record of this specific name being published according to the rules of nomenclature. The South American plants given this specific name, are taxonomically identical with $O$. alta Swallen, and according to the rules this latter would be the valid name.

4) o. latifolia Desv. This name has been applied to two different species, one distributed in Tropical America and the other in Asia and possibly in Africa. The specific name $O$. latifolia is validly applicable to the American species which is a tetraploid $(2 \mathrm{n}=48)$. The Asian species is diploid $(2 \mathrm{n}=24)$ and is classifiable as $O$. officinalis Wall. In the standard book on Flora of British India, by Hooker, this species is listed as O. latifolia and the error has been copied by others. Chatterjee ${ }^{1}$ ) uses the character, ligule fringes, to discriminate between the two species, the tetraploid $O$. latifolia having fringed ligules, the diploid $O$. officinalis not having the fringes. This distinction is not absolute, because new observations have shown

* Colombo Plan Associate: National Institute of Agricultural Sciences, Hiratsuka, Japan. 
the occurrence of fringes in new varieties of $O$. officinalis collected from Bombay State, from Thailand, and from China. In addition to this, a tetraploid species resembling $O$. officinalis has been recently collected from Kerala, India, by Krishnaswamy and Chandrasekaran $^{3}$ ). This species has light fringing on ligules. It is desirable that a cytogenetic study of this species, along with new African collection at National Institute of Genetics, Mishima, be completed and species delimitations made. Till such a study is completed, it is desirable to use $O$. latifolia as the specific name for the American species, and $O$. officinalis for the Asian species.

5) 0. grandiglumis (Doell) Prodoehl. Since the specific name implies increased size of glumes (sterile lemma), it has been wrongly applied to varieties of $O$. sativa and of $O$. glaberrima which had long glumes (e.g. Sampath and $\left.\mathrm{RaO}^{4}\right)$ ). In O. ridleyi also, the setaceous glumes are long, and this species has once been described as $O$. grandiglumis. The name is valid for an American species having the chromosome number $2 \mathrm{n}=48$. This species closely resembles $O$. latifolia Desv. and recent cytogenetical work at the National Institute of Agricultural Sciences, Hiratsuka, suggests that it is closely related to both $O$. latifolia and $O$. alta.

6) 0. meyeriana (Zoll. et Mor.) and 0. granulata Nees et Arn. These two species have been united by some taxonomists, and the Indian species is listed as $O$. meyeriana in some Floras. Both Chatterjee ${ }^{1}$ ) and Backer $^{5}$ ) have recorded that they are distinct and that the Indian species is $O$. granulata. This is diploid $(2 \mathrm{n}=24)$ and suggestion by Sampath and $\mathrm{RaO}^{4}$ ) that it is tetraploid is wrong. O. meyeriana is an Indonesian species and $O$. abromeitiana is a synonym of this species. The chromosome number of this species is not established as the publications listing it as diploid do not show whether the genuine $O$. meyeriana was studied.

7) 0. punctata Kotschy ex Steud. The taxonomy of this species requires further study. Sasaki ${ }^{6}$ ) has indicated that this African species is similar to O. officinalis of Asia, as well as to O. latifolia of America. Chatterjee ${ }^{1}$ ) does not record the occurrence of $O$. officinalis in Africa. He distinguishes $O$. punctata from the latter in having longer spikelets $(6-6.5 \mathrm{~mm}$. long), longer awns (30-70 mm.) and longer ligules (4-6 mm.). Ligules are not fringed as they are in American species. A sample of seeds received from Belgian Congo were grown and studied. The Belgian taxonomists identify it as $O$. schweinfurthiana, a perennial type of $O$. punctata. This species had spikelets smaller than the limits for $O$. punctata, had the tetraploid chromosome number $(2 \mathrm{n}=48)$ and was resembling $O$. eichingeri, another tetraploid species from East Africa. This collection is probably a new variety of $O$. eichingeri. It is also possible that $O$. punctata is a diploid species closely akin to $O$. officinalis and more variable than recognized by Chatterjee.

I am indebted to the Government for an award under Colombo Plan, which has enabled me to study botanical researches on rice in Japan. I am also indebted to Prof. T. Morinaga for facilities and encouragement.

\section{References}

1) Chatterjee, D., Ind. J. Agric. Sci. 18: 185 (1948). 2) Kihara, H., Seiken Ziho 10: 68 (1959). 3) Krishnaswamy, N., and Chandrasekaran, P., Sci. and Cult. 23: 308 (1957). 4) Sampath, S., and Rao, M. B. V. N., Ind. J. Genet. Plt. Breed. 11: 14 (1951). 5) Backer, C. A., Blumea Suppl. 3: 44 (1946). 6) Sasaki, T., "On the distribution of Oryza species", (Japanese). Sakumotsugaku Ronshu, Kikkawa Kyoju Zaishoku 25 nen Kinenkai (1935). 